\title{
Protocol for improving nursing performance towards placental examination at labor units
}

\author{
Hanan Elzeblawy Hassan*1, Shaimaa Hassan Mohamady², Neama Abd El-Fattah Abd El-Gawad ${ }^{2}$ \\ ${ }^{1}$ Maternal \& Newborn Health Nursing, Faculty of Nursing, Beni-Suef University, Egypt \\ ${ }^{2}$ Maternal \& Newborn Health Nursing, Faculty of Nursing, Helwan University, Egypt
}

Received: October 31, 2016

Accepted: December 28, $2016 \quad$ Online Published: February 28, 2017

DOI: $10.5430 /$ cns.v5n2p1

URL: http://dx.doi.org/10.5430/cns.v5n2p1

\begin{abstract}
Objective: The placenta is derived from both maternal and fetal tissue with approximately one fifth derived from fetal tissue at term. The placenta should be examined, as it reflects disease in the mother and the fetus. Aim: The aim is to implement a protocol for improving nursing performance towards placental examination at labor units.

Methods: Design: A quasi-experimental design was adopted. Setting: The current study was conducted at the labor unit at Ain Shams maternity hospital and Beni-Suef University hospital. Sample: 42 nurses who were affiliated to labor units (21 nurses of Ain Shams maternity hospital group and 21 nurses of Beni-Suef University hospital group). Tools: Two tools were used for data collection; structured interview questionnaire and an observation checklist.

Results: There was no significant difference between both groups in general characteristics. The majority of the studied nurses from Ain Shams and Beni-Suef hospital, respectively, did not attend any training related to placental examination before conducting the study. Meanwhile, there was a significant improvement in nurses' performance towards placental examination after implementing the program.

Conclusions: The placental examination program was effective in improving the nurse's performance at labor units.

Recommendation: Policymakers should formulate a national plan of continuing education to help nurses already in the labor force to retain and update their knowledge and clinical skills especially in such topic placental examination and encourage nurses to participate in programs in order to maintain a high level of health care in maternity hospitals.
\end{abstract}

Key Words: Placental examination, Nursing performance

\section{INTRODUCTION}

The placenta is a fetal organ consisting of an umbilical cord, membranes, and parenchyma. Maternal or fetal disorders may have a placental sequel since the mother and fetus interface on this site. The placenta is derived from both fetal and maternal tissues with about one-fifth derived from fetal tissue at term. It comprises a large number of functional units called villi which are branched terminals of the fetal circulation, allowing transfer of metabolic products. ${ }^{[1]}$
The structure of the placenta is disc-shaped with each fetal and maternal surface. At term, the normal placenta weighs about $500 \mathrm{~g}$ to $600 \mathrm{~g}$ and has a diameter of $15 \mathrm{~cm}$ to $20 \mathrm{~cm}$. The fetal surface is made up of cotyledons, which are further divided into lobules. The outer appearance is shiny and white in nature due to the chorionic plate and the amnion covering. The maternal surface is dark red in color and is made up of 15 to 20 cotyledons, which are divided by septa. Insignificant changes can occur, like infarctions related to the depositing

\footnotetext{
*Correspondence: Hanan Elzeblawy Hassan; Email: nona_nano_1712@yahoo.com; Address: Maternal \& Newborn Health Nursing, Faculty of Nursing, Beni-Suef University, Egypt.
} 
of fibrin, and also the surface can seem gritty due to lime salt deposits. ${ }^{[2,3]}$

The cord is usually inserted in the center of the fetal surface with blood vessels branching outwards. The umbilical cord usually contains one vein and two umbilical arteries; they are surrounded by Wharton's jelly and covered by the amnion. The cord is twisted spirally so as to safeguard the vessels and it's about $40 \mathrm{~cm}$ to $50 \mathrm{~cm}$ in length. ${ }^{[4]}$

Primary placental abnormalities can effect on each fetal and maternal health. Thus, examination of the placenta could yield information on the impact of maternal disorders on the fetus or the reason behind preterm delivery, neurodevelopmental impairment, or fetal growth restriction. Benefits of placental examination include clarification of the reason behind several adverse gestation outcomes, ascertainment of newborn risk factors for long-term neurodevelopmental sequelae, and improvement in the risk assessment for future pregnancies. ${ }^{[4]}$

The placental examination is an essential component of the autopsy in cases of fetal or neonatal death. This examination additionally aids in adjudicating a number of difficult situations, such as legal issues regarding the presence of acute versus chronic perinatal stresses and insults, and the timing of these insults. It additionally supports the diagnosis of specific etiologies associated with adverse gestation outcomes. $^{[1]}$

Artymuk V et al. ${ }^{[5]}$ emphasized that initial examination of the placenta should be performed wherever the birth occurred. This should note the cord insertion in the fetal surface, the number of cord vessels, total cord length, membranes, the presence of amnion \& chorion, the presence of offensive odor, and, finally, completeness and cloudiness. It should be followed by an examination of the maternal surface for texture, completeness, extra cotyledons and areas of a possible infarct. The results should be documented within the mother's obstetric case worksheet. A fresh specimen of the placenta will be collected if special studies are required. The entire placenta, including the entire length of umbilical cord, should be sent to anatomical pathology if either the examination was abnormal. Nurses should ensure a detailed pathology request form is filled out listing indications for anatomical pathology review. It must include gestational age, Hepatitis C and HIV status. ${ }^{[5]}$

\subsection{Significance of the study}

There is a general consensus that all placentas should be examined grossly, as it effectively provides a record of pregnancy-related events and changes to the intrauterine environment. ${ }^{[6]}$ The information that the placenta contains is often unavailable from any other source. The necessary examination will vary with the clinical situation and ranges from simple visual inspection to detailed molecular examination. ${ }^{[7,8]}$

After the birth of the baby, if the placenta is retained, the mother may experience vaginal bleeding leading to hypovolemic shock and death. So the nurse has a major role in assessing and examining the placenta thoroughly, as it helps to prevent the maternal complications, improves the mother's health and facilitates a reduced maternal morbidity and mortality rate..$^{[9,10]}$

According to World Health Organization (WHO) 2015, maternal mortality is unacceptably high. Ninety-nine percent of all maternal deaths occur in developing countries. Every day, around 830 women die from preventable causes related to pregnancy \& childbirth. As is well documented, the healthcare solutions to avoid and/or manage complications include universal access to antenatal care throughout pregnancy, skilled care throughout childbirth, and care and support in the postnatal period. ${ }^{[11]}$

As regards to Brown $\mathrm{H}$ et al. ${ }^{[12]}$ and Filippi $\mathrm{C}$ et al., ${ }^{[13]}$ an estimated 300,000 women died globally in 2015 as a result of pregnancy-related conditions. The findings of the World Health Organization meta-analysis show that the foremost important direct causes are haemorrhage (27\%), abortion, and sepsis (14\%) and hypertension (11\%), Postpartum haemorrhage could be a major explanation for maternal morbidity worldwide. It is also associated with anaemia, which might persist for many months after birth. Filippi $\mathrm{C}$ et al. ${ }^{[13]}$ added that the proportion of deaths from haemorrhage globally remains high although interventions to prevent and treat the direct causes of maternal death such as active management of the third stage of labor have been well established.

Postpartum infections and Puerperal Sepsis, if the placenta is retained,also comprise a wide range of entities that may occur either after vaginal or caesarean delivery and/or throughout breastfeeding. ${ }^{[14]}$ In a study by Yokoe et al. in 2001, 7.4\% of cesarean deliveries \& $5.5 \%$ of vaginal deliveries resulted in a postpartum infection. ${ }^{[15]}$ So, it is particularly important that all births are attended by skilled health professionals, as time management and treatment may mean the distinction between life and death for the mother and the baby. Severe haemorrhage after birth can kill a healthy woman within hours if she remains unattended. Postpartum infection can be eliminated if sensible hygiene is practiced and also if early signs of infection are recognized and treated in a timely manner. ${ }^{[11]}$ Lastly, the international and national shortage of specific studies regarding the existing study of placental examination was motivated by the researcher' desire to in- 
vestigate the situation and to enhance the nurses' knowledge and skills.

\subsection{Aim of the study}

The aim of the current study was to implement a protocol for improving nursing performance towards placental examination at labor units. This aim will be fulfilled through the following objectives:

- Assess the nurses' knowledge of placental examination at two labor units.

- Assess the nurses' performance toward placental examination at two labor units.

- Implement a protocol regarding placental examination for nurses working at labor units.

- Assess the effect of the protocol on nurses' longer-term knowledge and performance.

\subsection{Research hypothesis}

Nurses' knowledge and performance will be improved after implementing the protocol.

\section{SubJeCtS AND MeThodS}

Subjects and methods of the present study were represented under four main topics, namely technical, operational, administrative and statistical design.

\subsection{Technical design}

The technical design for the study included the research design, setting of the study, sampling, and tools for data collection.

\subsubsection{Study design}

A quasi-experimental design was adopted to conduct the current study.

\subsubsection{Setting}

This study was conducted at two settings: a labor unit of the maternity hospital affiliated with Ain Shams University and a labor unit affiliated with Beni-Suef University hospital.

\subsubsection{Sampling}

(1) Type of Sample: Purposive sample.

(2) Subject: Nurses working at labor unit regardless their age, the level of education and years of experience (42 nurses).

- Inclusion criteria:

(i) The nurses who were responsible for providing nursing care for laboring women.

(ii) All levels of nursing education.

- Exclusion Criteria: The nurses who had an administrative role only as the head nurses.

\subsubsection{Tools}

The data collection instruments were developed by the researchers following literature review related of placental examination. Two tools were used for data collection.

First tool: A Structured interviewing questionnaire: consisted of two parts:

Part 1 consists of closed end questions as multiple-choice questions (MCQ). It was developed to collect sociodemographic characteristics of the participant nurses such as age, educational level and years of experience.

Part 2 was developed to collect data related to the nurses' knowledge regarding placental examination which included signs and symptoms of placental separation, characteristics of the normal placenta as well as placental abnormalities in form of open end questions (define, list and short answer). This part was delivered to the participant nurses four times; at pretest, at posttest, after three months and after six months. The scoring system was coded as follows:

- The correct complete answer $=(2)$ score

- The correct incomplete answers = (1) score

- The Incorrect incomplete answers = (0) score

Second tool: An Observational checklist was developed to collect data related to nurses' practices about the placental examination. (This tool was used to observe the participant nurses three times: at the beginning of the study, after three months, and after six months). The scoring system was coded as follows:

- No = 0: if the observed item was not found

- Yes =1: if the observed item was found

\subsection{Operational design}

\subsubsection{Preparatory phase}

(1) Review of literature about placental examination. This included a review of current and past, national and international literature.

(2) Development of the tools and applying validity and reliability.

- Validity was established after a detailed review of literature related to placental examination. The original questions were revised and expanded to improve clarity, precision, and to develop comprehensive question sets about placental examination. The tool is revised three experts: (i) medical, and (ii) nursing experts for assessment of validity, accuracy, completeness, and ease of completion.

- Reliability analysis was used to verify the extent to which the items in the questionnaire are related to 
each other. Confirming the stability of the questionnaire, Cronbach's alpha was used because it gives the minimum reliability coefficient scale, beside it does not require replication, and it has been shown that the Cronbach's alpha coefficient equal to 0.76 is an excellent factor in such studies. The results of the pilot study were also used to confirm the reliability (test-retest reliability). The findings suggested that the current questionnaire is a viable tool for data collection in this study.

\subsubsection{Pilot study}

A pilot study was conducted for $10 \%$ of the nurses (5 nurses) to test for clarity, simplicity, and applicability of the tools. No modification was done and the participants of the pilot study were excluded from the study sample.

\subsubsection{Field work}

The study was carried out through the following phases: assessment, planning, implementation, follow-up and evaluation phase.

- Assessment phase: Official permission was obtained to perform the study. Nurses were selected according to the previously mentioned criteria. Before embarking on data collection the aim of the study was explained to them. The nurses were informed that the interview was voluntary and anonymous. Each nurse was interviewed individually to complete the structured interview questionnaire and the checklist. This took 25-30 minutes.

- Planning phase: The protocol was previously designed by the researchers and modified according to the results obtained from the assessment phase and relevant review of literature.

- Implementation phase: All volunteer nurses participated in the protocol activities such as lectures and demonstration of placental examination. It consisted of four sessions in front of nurses in small groups. Four groups were established, 5 nurses in each group except the last one comprising 6 nurses.

(i) First session: covered basic topics such as anatomy and physiology of the placenta. The aim of the session was to increase the nurses' knowledge of the normal anatomical characteristics and physiological process of the placenta.

(ii) Second session: aimed to increase the nurses' knowledge regarding delivery of the placenta. It covered signs of placental separation; duration; and, nurses' role during delivery of the placenta.

(iii) Third session: aimed to increase the nurses' knowledge regarding placental abnormalities. It covered dif- ferent types of abnormalities, adverse health effects on both mother and fetus and nursing management.

(iv) Fourth session: aimed to improve the nurses' knowledge and performance toward placental examination. It covered steps of placental examination procedure and its importance followed by a demonstration. Repeat demonstrations occurred 3-4 times.

Each session took about 45-60 minutes using simple language to suit nurses' level of understanding. At the end of each session, feedback was invited; nurses' questions were discussed to explain any misunderstanding. Different methods of teaching were used such as lectures, group discussion, demonstration, and repeat demonstration.

- Follow up and evaluation phase: During this phase, the impact of the protocol was evaluated by using the same format of data collection tools. The immediate evaluation was conducted as a posttest. Another two subsequent follow up phases were scheduled; three months and six months later.

Data were collected for three days per week according to the available time to nurses and their attendance shift schedule. The actual field work was carried out from the beginning of July 2014 up to the end of December 2014.

\subsection{Administrative approval}

An official letter was obtained from the Faculty of Nursing - Helwan University to both Hospitals of Ain Shams University and Beni-Suef University after which time the study began.

\subsection{Ethical approval}

Before inclusion in the study sample, each nurse gave her oral informed consent to participate in the current study. She was informed that participation in the study was totally voluntary, and that she could withdraw from the study whenever she decided. The aim and objectives of the study were clarified to each nurse included in the study. Total confidentiality to obtain information as well as respect for privacy was ensured.

\subsection{Statistical design}

The data collected were tabulated \& analyzed by the SPSS statistical package version 14. Quantitative data were expressed as mean and standard deviations $(\mathrm{X} \pm S D)$ and analyzed for comparison of two groups of normally distributed variables. Qualitative data were expressed as number and percentage (number and percent). Data were analyzed by applying chi-square and $t$-test. All those tests were used as tests of significance at $p$-value $<.05$. 


\section{RESULTS}

The results of this study will be presented in 3 parts:

Part I: General characteristics of the study sample (see Table 1).

Part II: Knowledge of the study sample regarding the placenta and placental examination (see Tables 2-4).

Part III: Performance and satisfaction of the study sample regarding placental examination (see Table 5 and Figures 1-3).

Part I: General characteristics of the study sample.

Table 1 shows the general characteristics of the study sample. It illustrates that more than half of nurses $(61.9 \%$ and 57.2\%), of Ain shams and Beni-Suef hospitals, respectively were in age group 30+ years, and their mean age was $30.96 \pm 5.69$ years and $28.34 \pm 5.28$, respectively. More than half of nurses (66.7\% and 57.2\%) of both groups had secondary educational level. Regarding their years of experience $(47.6 \%$ and $42.9 \%$ ), nurses in both groups had more than fifteen years of experience, and (19.0\% and $23.8 \%)$ had $1-5$ years of experience and the means $\pm S D$ is $(2.90 \pm 1.22$ and $2.76 \pm 1.26$ ). There is no statistically significant difference between Ain shams and Beni-Suef groups regarding socio-demographic characteristics.

Part II: knowledge of the study sample regarding the placenta and placental examination.

Table 2 illustrates the attendance of the studied nurses of any educational training related to placental examination during their work years. Ninety-five of the studied nurses from Ain shams hospital and $66.6 \%$ of the studied nurses from BeniSuef hospital did not attend any training related the placental examination.

Table 1. Socio-demographic characteristics of the study sample $(n=42)$

\begin{tabular}{|c|c|c|c|c|c|c|}
\hline \multirow{2}{*}{ Items } & \multicolumn{2}{|c|}{ Ain Shams Group $(n=21)$} & \multicolumn{2}{|c|}{ Beni-Suef Group $(n=21)$} & \multicolumn{2}{|c|}{ Significant test } \\
\hline & No & $\%$ & No & $\%$ & $\chi^{2}$ & $p$ \\
\hline \multicolumn{7}{|l|}{ Age in years: } \\
\hline $20-$ & 3 & 14.3 & 3 & 14.3 & \multirow{4}{*}{1.298} & \multirow{4}{*}{.205} \\
\hline $25-$ & 5 & 23.8 & 6 & 28.5 & & \\
\hline $30+$ & 13 & 61.9 & 12 & 57.2 & & \\
\hline Mean $\pm S D$ & \multicolumn{2}{|c|}{$30.96 \pm 5.69$} & \multicolumn{2}{|c|}{$28.34 \pm 5.28$} & & \\
\hline \multicolumn{5}{|l|}{ Education: } & \multirow{4}{*}{0.787} & \multirow{4}{*}{.853} \\
\hline Secondary school & 14 & 66.7 & 12 & 57.2 & & \\
\hline Technical Institute & 3 & 14.3 & 8 & 38.0 & & \\
\hline Faculty of nursing & 4 & 19.0 & 1 & 4.8 & & \\
\hline \multicolumn{5}{|l|}{ Experiences years: } & \multirow{6}{*}{0.334} & \multirow{6}{*}{.523} \\
\hline $1-5$ years & 4 & 19.0 & 5 & 23.8 & & \\
\hline $6-10$ years & 4 & 19.0 & 4 & 19.0 & & \\
\hline $11-15$ years & 3 & 14.4 & 3 & 14.4 & & \\
\hline$>15$ years & 10 & 47.6 & 9 & 42.8 & & \\
\hline Mean $\pm S D$ & \multicolumn{2}{|c|}{$2.90 \pm 1.22$} & \multicolumn{2}{|c|}{$2.76 \pm 1.26$} & & \\
\hline
\end{tabular}

Table 2. Educational training related to placental examination

\begin{tabular}{|c|c|c|c|c|c|c|}
\hline \multirow{2}{*}{ Attend training } & \multicolumn{2}{|c|}{ Ain Shams $(n=21)$} & \multicolumn{2}{|c|}{ Beni-Suef $(n=21)$} & \multicolumn{2}{|c|}{ Significant test } \\
\hline & No & $\%$ & No & $\%$ & $\chi^{2}$ & $p$ \\
\hline Yes & 1 & 4.7 & 7 & 33.4 & 555 & $0^{*}$ \\
\hline No & 20 & 95.3 & 14 & 66.6 & 5.55 & .020 \\
\hline
\end{tabular}

mild statistically significant

Table 3 illustrates that the studied nurses have a lack of knowledge regarding the placenta in the pretest. Approximately $60 \%$ of them can't define the placental barrier, or the placental general characteristics $(47.6 \%)$ and $45.2 \%$ of them can't mention the recent benefits or uses of it. Additionally,
$26.2 \%$ of them couldn't determine the site of placental implantation. A similar percent, $35.7 \%$ couldn't determine the time of placental formation and its functions. While in the post-test they achieved a high level of knowledge regarding all the previously mentioned items. 
According to Table 4, all the studied nurses from both hospi- ever, a slight mean decline for both of them occurred after tals, show a general improvement in all items of knowledge related to placental examination. This result was noticeable during the different assessment phases as compared to their three and six months. Highly statistically significant difference observed between the four times of assessments at level of knowledge before implementing the protocol. How$p$-values $<.001$.

Table 3. Pre-post nurses' knowledge regarding the placenta

\begin{tabular}{|c|c|c|c|c|c|c|c|c|c|c|c|c|c|}
\hline \multirow{3}{*}{ Items } & \multicolumn{6}{|c|}{ Pre-test $(n=42)$} & \multicolumn{6}{|c|}{ Post-test $(n=42)$} & \multirow{3}{*}{$p$} \\
\hline & \multicolumn{2}{|c|}{ Correct } & \multicolumn{2}{|c|}{$\begin{array}{l}\text { Correct } \\
\text { incomplete }\end{array}$} & \multicolumn{2}{|c|}{ Incorrect } & \multicolumn{2}{|c|}{ Correct } & \multicolumn{2}{|c|}{$\begin{array}{l}\text { Correct } \\
\text { incomplete }\end{array}$} & \multicolumn{2}{|c|}{ Incorrect } & \\
\hline & No & $\%$ & No & $\%$ & No & $\%$ & No & $\%$ & No & $\%$ & No & $\%$ & \\
\hline Define corpus luteum & 7 & 16.7 & 25 & 59.5 & 10 & 23.8 & 42 & 100 & 0.0 & 0.0 & 0.0 & 0.0 & $>.05$ \\
\hline Time of placental formation & 11 & 26.2 & 16 & 38.1 & 15 & 35.7 & 42 & 100 & 0.0 & 0.0 & 0.0 & 0.0 & $<.001^{* * * * *}$ \\
\hline Site of implantation & 16 & 38.1 & 15 & 35.7 & 11 & 26.2 & 42 & 100 & 0.0 & 0.0 & 0.0 & 0.0 & $<.001^{* * * *}$ \\
\hline Functions of the placenta & 16 & 38.1 & 11 & 26.2 & 15 & 35.7 & 42 & 100 & 0.0 & 0.0 & 0.0 & 0.0 & $<.001^{* * * *}$ \\
\hline Define placental barrier & 7 & 16.7 & 10 & 23.8 & 25 & 59.5 & 40 & 95.2 & 2 & 4.8 & 0.0 & 0.0 & $<.001^{* * * *}$ \\
\hline Characteristics of placenta & 8 & 19 & 14 & 33.3 & 20 & 47.6 & 42 & 100 & 0.0 & 0.0 & 0.0 & 0.0 & $<.001^{* * * *}$ \\
\hline Recent benefits of it & 10 & 23.8 & 13 & 31 & 19 & 45.2 & 39 & 92.9 & 3 & 7.1 & 0.0 & 0.0 & $<.001^{* * * *}$ \\
\hline
\end{tabular}

*** highly statistically significant

Table 4. Nurses' knowledge regarding placental examination

\begin{tabular}{|c|c|c|c|c|c|c|c|c|c|c|c|}
\hline \multirow{2}{*}{ Hospital } & \multirow{2}{*}{$\begin{array}{l}\text { Assessment time } \\
\text { Items }\end{array}$} & \multirow{2}{*}{$\begin{array}{l}\begin{array}{l}\text { Before } \\
\text { program } \\
(\mathrm{n}=21)\end{array} \\
\text { Mean } \pm S D\end{array}$} & \multicolumn{3}{|c|}{ Immediately after $(n=21)$} & \multicolumn{3}{|c|}{ After 3 month $(\mathrm{n}=\mathbf{2 1})$} & \multicolumn{3}{|c|}{ After 6 months $(n=21)$} \\
\hline & & & Mean $\pm S D$ & $\begin{array}{l}\text { Paired } \\
\left(t_{1}\right)\end{array}$ & $p$ & Mean $\pm S D$ & $\begin{array}{l}\text { Paired } \\
\left(t_{2}\right)\end{array}$ & $p$ & Mean $\pm S D$ & $\begin{array}{l}\text { Paired } \\
\left(\mathbf{t}_{3}\right)\end{array}$ & $p$ \\
\hline \multirow{7}{*}{$\begin{array}{l}\text { Ain } \\
\text { Shams } \\
\text { university }\end{array}$} & $\begin{array}{l}\text { - Knowing placental } \\
\text { examination. }\end{array}$ & $0.58 \pm 0.56$ & $1.64 \pm 0.48$ & 15.23 & $<.001^{3 * F}$ & $1.29 \pm 0.45$ & 12.98 & $<.001^{1 * * F}$ & $1.14 \pm 0.34$ & 9.16 & $<.001^{* 3 \% F}$ \\
\hline & $\begin{array}{l}\text { - Importance of } \\
\text { placental } \\
\text { examination. }\end{array}$ & $0.25 \pm 0.44$ & $1.00 \pm 0.00$ & 18.53 & $<.001^{* * *}$ & $1.00 \pm 0.00$ & 18.53 & $<.001^{* * *}$ & $1.00 \pm 0.00$ & 18.31 & $<.001^{* * *}$ \\
\hline & $\begin{array}{l}\text { - Time needed for } \\
\text { placental separation. }\end{array}$ & $0.52 \pm 0.50$ & $1.44 \pm 0.49$ & 14.46 & $<.001^{* * *}$ & $1.10 \pm 0.36$ & 10.28 & $<.001^{* * * *}$ & $1.04 \pm 0.19$ & 9.93 & $<.001^{* * * *}$ \\
\hline & - Signs of separation. & $1.29 \pm 0.45$ & $2.00 \pm 0.00$ & 17.00 & $<.001^{* * *}$ & $1.81 \pm 0.39$ & 10.37 & $<.001^{* * * *}$ & $1.75 \pm 0.44$ & 8.38 & $<.001^{* * * *}$ \\
\hline & - Surfaces of placenta. & $0.76 \pm 0.57$ & $1.86 \pm 0.34$ & 17.82 & $<.001^{* * *}$ & $1.66 \pm 0.48$ & 12.55 & $<.001^{* * *}$ & $1.55 \pm 0.50$ & 10.18 & $<.001^{* * *}$ \\
\hline & - Weight of placenta. & $0.52 \pm 0.50$ & $1.44 \pm 0.49$ & 14.46 & $<.001^{* * * *}$ & $1.10 \pm 0.36$ & 10.28 & $<.001^{* * * *}$ & $1.04 \pm 0.19$ & 9.93 & $<.001^{* * * *}$ \\
\hline & - Abnormalities of it. & $0.44 \pm 0.56$ & $1.58 \pm 0.49$ & 15.74 & $<.001^{* * *}$ & $1.27 \pm 0.45$ & 13.45 & $<.001^{* * *}$ & $1.11 \pm 0.31$ & 10.47 & $<.001^{* * * *}$ \\
\hline \multirow{7}{*}{$\begin{array}{l}\text { Beni-Suef } \\
\text { university }\end{array}$} & $\begin{array}{l}\text { - Knowing placental } \\
\text { examination. }\end{array}$ & $1.29 \pm 0.45$ & $2.00 \pm 0.00$ & 17.00 & $<.001^{* * *}$ & $1.81 \pm 0.39$ & 10.37 & $<.001^{* * *}$ & $1.75 \pm 0.44$ & 8.38 & $<.001^{* * *}$ \\
\hline & $\begin{array}{l}\text { - Importance of } \\
\text { placental } \\
\text { examination. }\end{array}$ & $0.76 \pm 0.57$ & $1.86 \pm 0.34$ & 17.82 & $<.001^{* * *}$ & $1.66 \pm 0.48$ & 12.55 & $<.001^{* * *}$ & $1.55 \pm 0.50$ & 10.18 & $<.001^{* * *}$ \\
\hline & $\begin{array}{l}\text { - Time needed for } \\
\text { placental separation. }\end{array}$ & $0.52 \pm 0.50$ & $1.44 \pm 0.50$ & 14.48 & $<.001^{* * *}$ & $1.12 \pm 0.37$ & 10.39 & $<.001^{* * *}$ & $1.06 \pm 0.18$ & 9.97 & $<.001^{* * *}$ \\
\hline & - Signs of separation. & $0.58 \pm 0.49$ & $1.44 \pm 0.49$ & 14.74 & $<.001^{* * *}$ & $1.25 \pm 0.43$ & 10.53 & $<.001^{* * *}$ & $1.08 \pm 0.28$ & 9.19 & $<.001^{* * *}$ \\
\hline & - Surfaces of placenta. & $0.58 \pm 0.51$ & $1.56 \pm 0.49$ & 15.17 & $<.001^{* * *}$ & $1.34 \pm 0.48$ & 12.27 & $<.001^{* * * *}$ & $1.26 \pm 0.44$ & 11.02 & $<.001^{* * *}$ \\
\hline & - Weight of placenta. & $0.44 \pm 0.56$ & $1.58 \pm 0.49$ & 15.74 & $<.001^{* * *}$ & $1.27 \pm 0.45$ & 13.45 & $<.001^{* * *}$ & $1.11 \pm 0.31$ & 10.47 & $<.001^{* * *}$ \\
\hline & - Abnormalities of it. & $0.51 \pm 0.50$ & $1.35 \pm 0.48$ & 14.54 & $<.001^{* * *}$ & $1.06 \pm 0.24$ & 11.59 & $<.001^{* * * *}$ & $1.02 \pm 0.13$ & 10.25 & $<.001^{* * *}$ \\
\hline
\end{tabular}

Note. A statistical significant difference ( $p \leq .05)$; A highly statistical significant difference ( $p \leq .001)$; Paired (t1): Before program and immediately after; Paired (t2): Before program and after 3 months; Paired (t3): Before program and after 6 months; ${ }^{* * *}$ highly statistically significant

Part III: Performance and satisfaction of the study sample regarding placental examination

As regard to Figure 1, the nurses in both hospitals performed placental examination more frequently after implementing the protocol than before it.

According to Table 5, All the nurses from both hospitals showed a general improvement in all items of performance related to placental examination. This result was noticeable during the different assessment phases as compared to their level of performance before implementing the protocol. A highly statistically significant difference was observed between the three times of assessments at $p$-values $<.001$. It was an observable decline in knowledge but a continuing high level of performance regarding placental examination.

Figure 2 shows that the nurses were able to identify placental abnormalities after implementation of the protocol related to placental examination. Nineteen percent (19\%) of Ain Shames nurses and $14.3 \%$ of Beni-Suef nurses could already 
identify placental abnormalities specifically cord abnormalities such as a long cord around the fetal neck or limbs $37.5 \%$ $\& 25 \%$, and cord knots $25 \% \& 12.5 \%$ as well as placental surfaces abnormalities include missed cotyledon from the maternal surface of the placenta $12.5 \%$ \& $25 \%$, and missed part of the fetal membrane $25 \%$ and $12.5 \%$, respectively.

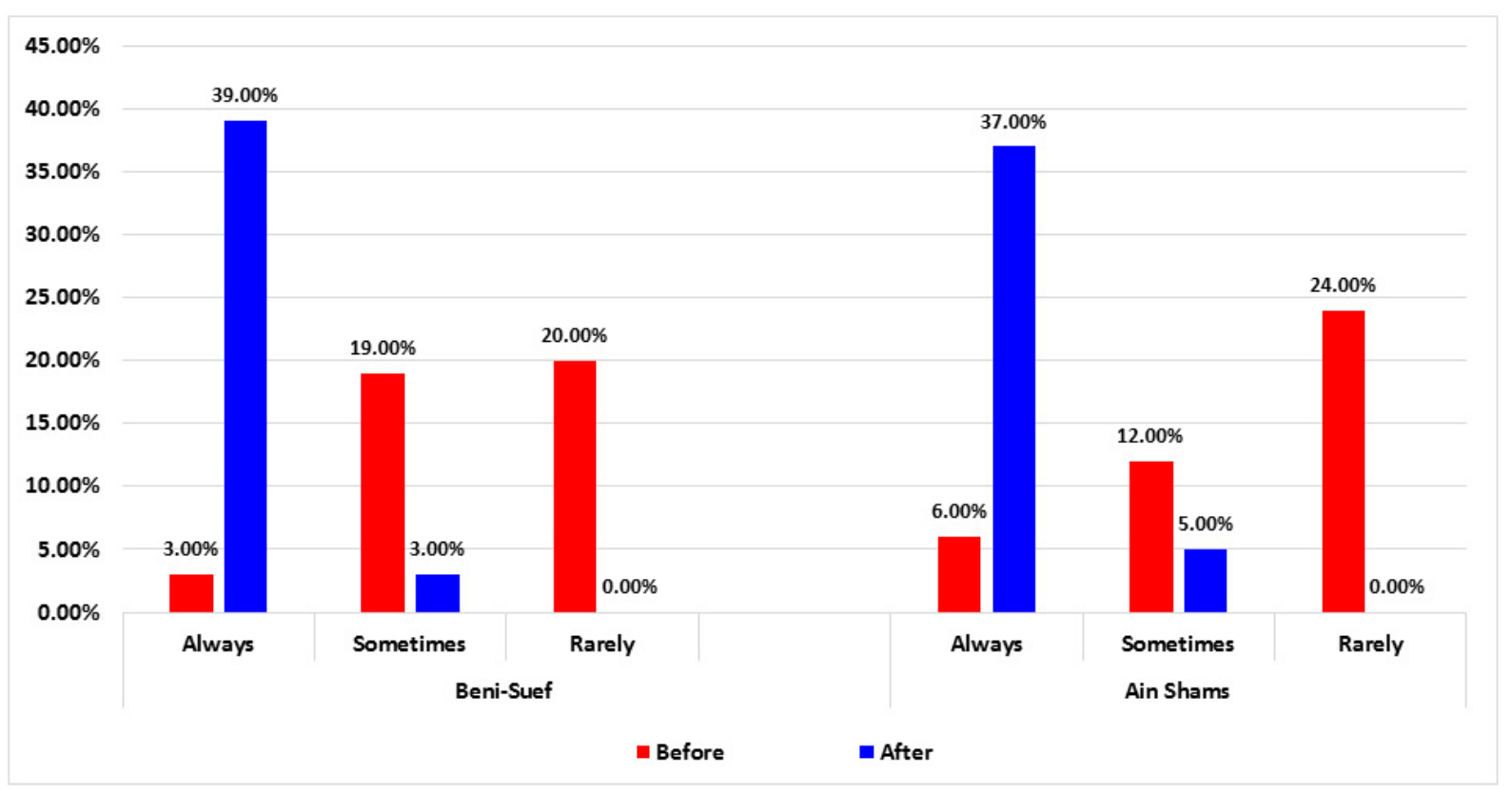

Figure 1. Placental examination before \& after implementing the protocol

Regarding nurses' satisfaction with participation in the protocol of placental examination, results in Figure 3 show that the majority of nurses had expressed their willingness to participate with a high level of satisfaction in both groups.

\section{Discussion}

As nurses comprise the greatest group of health care providers and are the ones responsible for the quality of care provided to the patients, their perspectives on the effectiveness of their care are very important, they should possess a wide variety of holistic skills and there is evidence of nursing interventions. ${ }^{[16-18]}$ Additionally, they should collaborate with other different health professionals to determine the effectiveness of therapy. ${ }^{[19]}$ They should also have the basic necessary knowledge and skills to offer the care safely, be trained accurately in practical and technical procedures to be able to use this knowledge effectively. ${ }^{[20]}$ As the nursing care is the main critical component of therapy in labor unit, Nurses' Knowledge deficit and poor manipulation of the third stage of labor surely will interfere with their ability to achieve positive prgnancy care outcomes. ${ }^{[21]}$ So, the aim of this study was implement a protocol for improving nursing performance towards placental examination at labor units.

The nurse should ensure that the woman is comfortable following the birth and should monitor the blood loss and check the uterus is well contracted. The examination of the placenta and membranes should take place as soon as possible following this in order to ensure that no further actions are required before the woman is discharged or transferred to the ward. ${ }^{[22]}$

According to the results of the current study, more than half of the study sample had a secondary level of nursing education and the majority of them had a low level of knowledge and performance toward placenta and placental examination before participation in the protocol. This is in agreement with the findings of Farag M. ${ }^{[23]}$ who found 3 types of nursing education relating to three types of nurses in Egypt today. The first level is carried out within high schools for nursing education akin to a sort of vocational education that takes place in lieu of high school (referred to as secondary level school in Egypt). The second level is carried out within a technical institute of nursing education (two years of after high school nursing education). The third or highest level is attained via a University college of nursing (students are trained over four years plus a one-year internship within a post-secondary school education or technical institute of nursing).

The health sector in Egypt suffers from a severe shortage of qualified nurses (nurses with at least technical institute, or 2 
years of post high school nursing education). The shortage has implications both for the quality of health care as well as the efficiency of the production of health services. The majority of nurses in Egypt (approximately 90\%) are high school level nurses reflecting an inadequate/insufficient quality of nursing education not only by internationally but even by the region's local standard. The current approach by the Ministry of Health and Population is to upgrade the standard of quality of nursing education in Egypt to eliminate high school level nursing education in the future; this seems to be the right approach. ${ }^{[24]}$

As mentioned above, the majority of the study nurses had a low level of knowledge toward placental examination prior to implementing the protocol. This result is not congruent with the results of the study conducted by the Royal Hospital for Women ${ }^{[25]}$ who stated that benefits of placental examination include: clarification of the reason for several adverse pregnancy outcomes, improvement in the risk assessment for future pregnancies and ascertainment of newborn risk factors for long-term neurodevelopmental sequelae. Additionally, information on placental abnormalities reveals the presence of chronic fetal insults and allows their differentiation from acute stresses. It is also supported by a study of stillbirths where $12 \%$ of causes of intrauterine fetal death (IUFD) were found in the fetus, and $88 \%$ of causes were found in the placenta, cord, and membranes. ${ }^{[26]}$

Table 5. Nurse's performance regarding placental examination

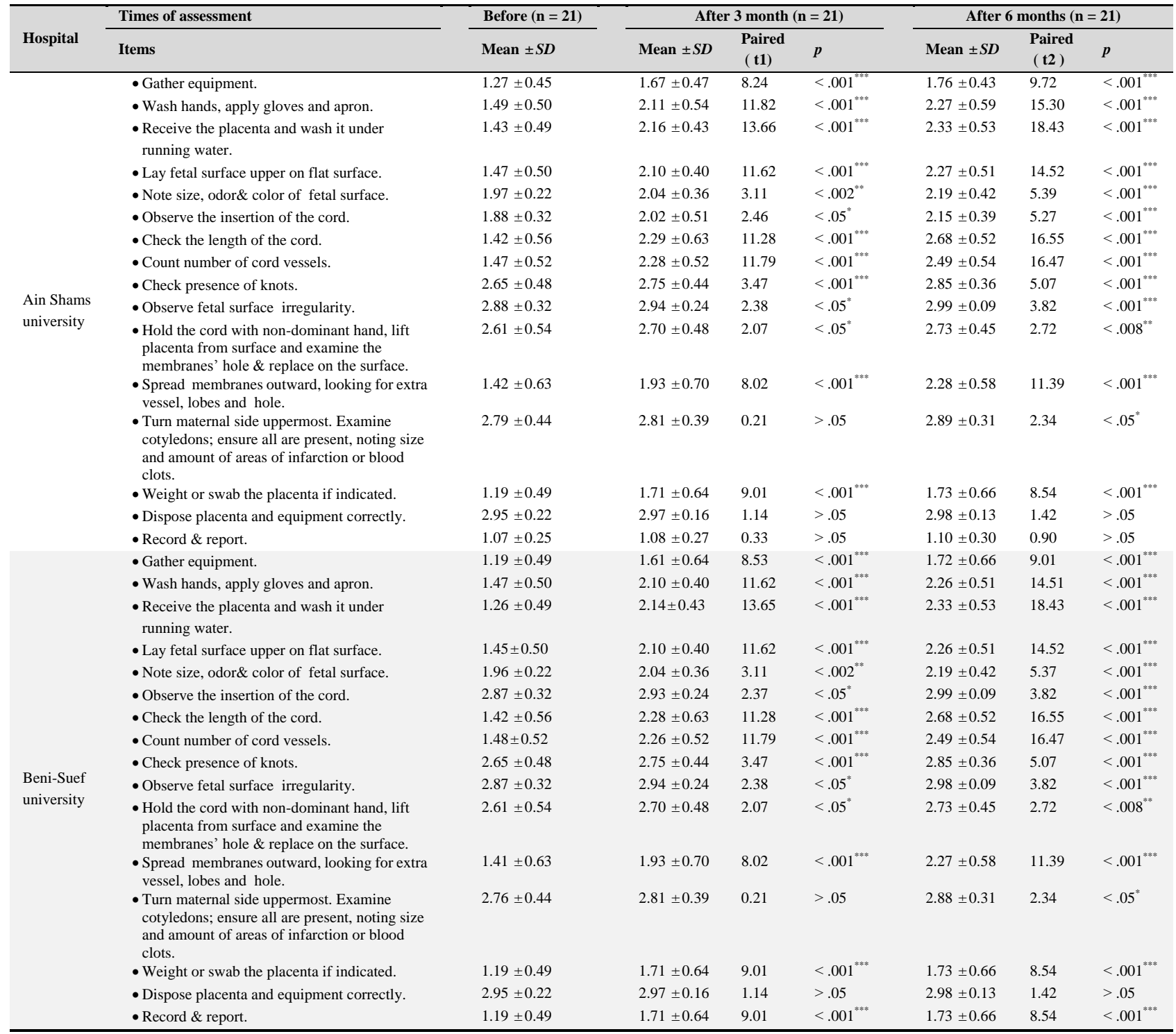

A statistical significant difference $(p \leq .05) ;{ }^{*}$ mild statistically significant; ${ }^{* *}$ moderate statistically significant; ${ }^{* * *}$ highly statistically significant; A highly statistical significant difference $(p \leq .001)$; Paired (t1): Before program and immediately after; Paired (t2): Before program and after 3 months; Paired (t3): Before program and after 6 months 

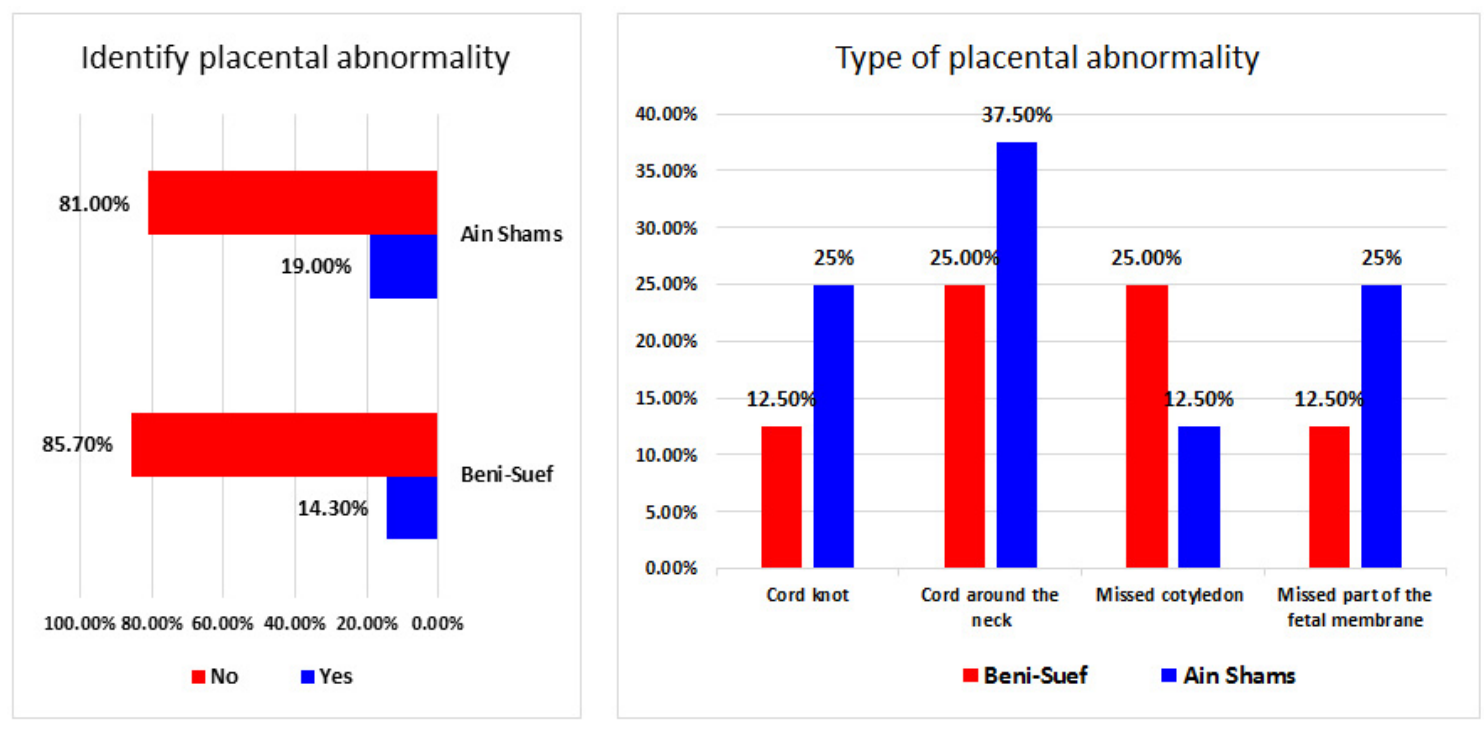

Figure 2. Identification of placental abnormalities after implementing the protocol

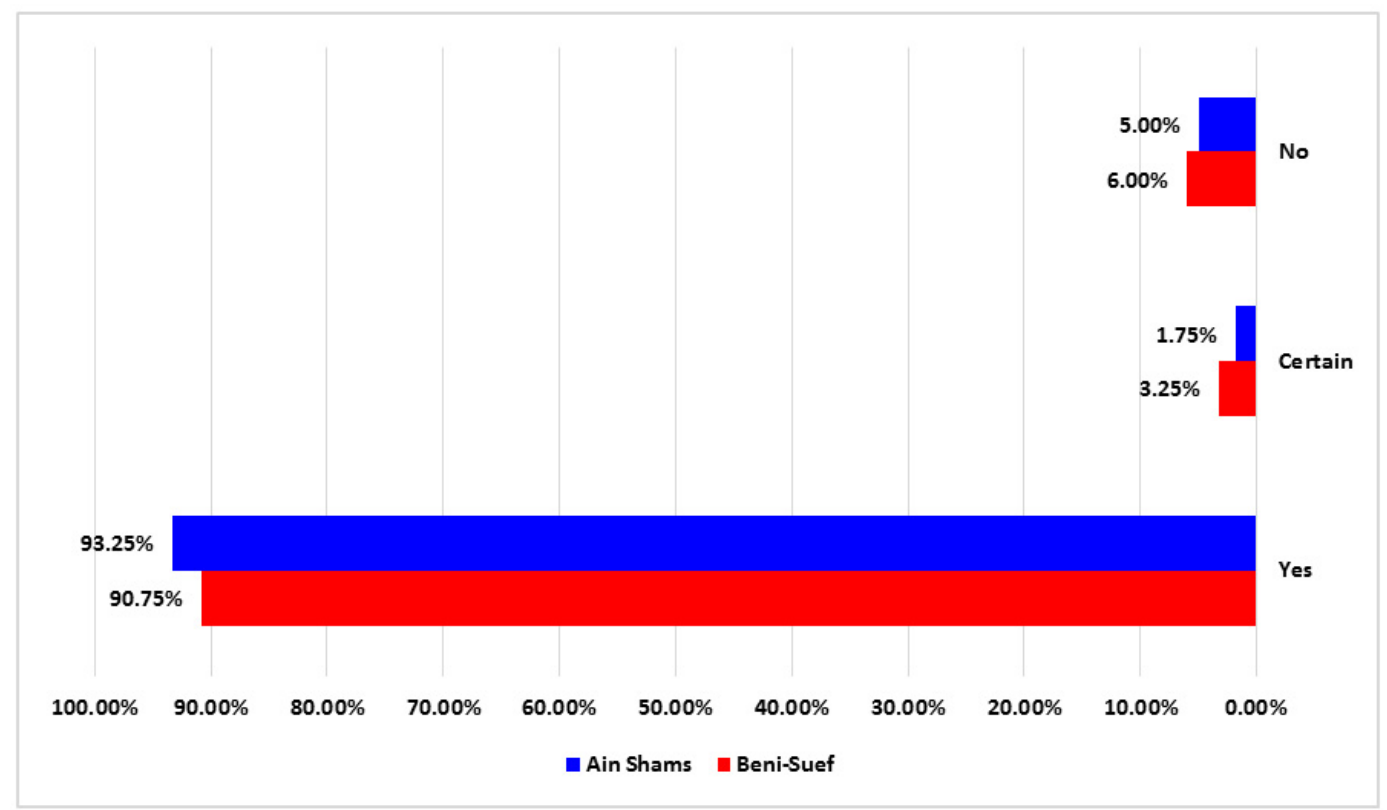

Figure 3. Nurses' satisfaction with participation in the protocol

Although there is a large body of literature that addresses placental examination guidelines, the findings of our study reflect severe malpractice among the study nurses regarding this important procedure. The majority of them did not perform it and the others did not perform it correctly or completely. According to King Edward Memorial Hospital 2015, this result is in line with an Australian study shown that less than $20 \%$ of placentas were examined, while up to $50 \%$ would have met the Guidelines of College of American Pathologist for placenta examination. ${ }^{[27]}$
This finding is also supported by Zuccollo $\mathrm{J}^{[26]}$ who mentioned that, in one survey, the authors found that the hospital staff examined only one-third of the placentas that were recommended using the practice guidelines of The American Pathologists College. This may be explained by the assumption held by the majority of the participants that their years of experience (10-15 years) qualified them to judge completeness and normality by only a cursory look at the placenta.

The current study revealed that the participants identified some cord and placental abnormalities such as long cord 
around the fetal neck and limbs, cord knots, missed cotyledon and missed part of the fetal membranes. This is in agreement with Hill, ${ }^{[28]}$ who found few abnormalities associated with umbilical cord development, other than abnormally short or long cords that in most cases do not cause difficulties. In some cases, however, long cords will wrap around limbs or the fetus neck, which might then restrict blood flow or cause tissue or nerve damage and therefore affect development. Cord knotting may also occur in about $1 \%$ of cases with little effect. However, cases of severe knotting can prevent the passage of placental blood.

This finding was also supported by Sudha ${ }^{[9]}$ who studied the effectiveness of a structured teaching program of placental examination among staff nurses at selected hospitals in Bangalore. The study revealed that the examination of the placenta can yield information that may be important within the immediate and later management of the mother and her infant. The conclusion was that all placentas should be examined in the delivery room to avoid maternal complications such as puerperal sepsis and postpartum hemorrhage.

It is also supported by Wong $\mathrm{W}$ et al. ${ }^{[29]}$ who mentioned that the presence of postpartum fever is mostly accepted among clinicians as a symptom of infection that has to be determined and managed. The typical pain that a lot of women feel within the immediate postpartum period also makes it difficult to discern postpartum sepsis from postpartum pain. Postpartum women are frequently discharged within two days following delivery. Yet this short period of observation may not afford enough time to exclude evidence of sepsis prior to hospital discharge. Accordingly, one study found $94 \%$ of postpartum infection cases were diagnosed after discharge from the hospital. This situation is mirrored in Egypt where most of the laboring women are discharged from the hospital within one or two days following normal vaginal delivery or even cesarean section delivery. ${ }^{[15]}$

Fraser DM \& Cooper MA ${ }^{[30]}$ also stressed that examination of the placenta and membranes should be performed as soon after birth as practicable so that, if there is doubt about their completeness, further action may be taken before the women leave the birth room or the midwife prepares to leave the home. A thorough inspection must be carried out in order to be sure that no parts of membranes or the placenta has been retained. The membranes are the most difficult to examine as they become torn during delivery and may be ragged.

Regarding documentation of the findings, the result of the present study illustrated that, nurses were not concerned about it; this was explained as the praticipant nurses working in university hospitals which usually have a high rate of labor as many Egyptian women prefer to deliver in university hos- pitals to ensure a high level of medical and nursing care. At the same time, the shortage of nurses means that most nurses are unable to record all their nursing activities in mothers' files. They usually prefer to consume their time in providing the needed nursing care rather than document it which is onerous and time-consuming. After the program, the praticipant nurses changed their attitudes regarding documentation. This is in agreement with Kennedy $\mathrm{M}$ et al. ${ }^{[31]}$ who recommended weighing the placenta if abnormally large or small and recording its weight in the maternity health record. This also supported by The Royal Berkshire Hospital, Practice Guidelines for the Examination of the Placenta Afterbirth ${ }^{[32]}$ which recommended that the nurse should document all of the findings and act accordingly. On checking the placenta and membranes the nurse should report any abnormalities to the labor ward coordinator and the appropriate medical professional. Finally, Kennedy et al. ${ }^{[31]}$ emphasized that, where there is a suspicion that membranes and/or the placenta are incomplete, they should be kept for any further inspection or examination and referred to the duty obstetrician.

\section{Conclusion}

Based on the results of our present study, it can be concluded that implementing a program of systematic placental examination significantly improved nurses' knowledge and performance at labor units in both Ain Shames and Beni-Suef hospitals.

\section{RECOMMENDATIONS}

\subsection{Based on the results of the current study}

It is recommended that:

(1) Policy makers should formulate a national plan of continuing education to help nurses already in the labor force to retain and update their knowledge and clinical skills.

(2) Health program managers need to continue to encourage nurses to participate in such programs in order to maintain a high level of health care in maternity hospitals.

(3) Replication of the study be carried out in other maternity settings, especially private hospitals and clinics.

\subsection{Further recommendation}

Investigate the birth attendance perception toward placental examination for women who deliver at home.

\subsection{Limitation of the study}

(1) Lack of references, few studies were done regarding nurses' knowledge and practices around placental examination. 
(2) Difficult communication and lack of cooperation with some nurses.

\section{CONFLicts OF InTEREST Disclosure}

None.

\section{REFERENCES}

[1] Vance M, Fraser D, Cooper M. The placenta: Myles textbook for midwives, $15^{\text {th }}$ ed. Edinburgh: Elsevier; 2009.

[2] Gulmezoglu M, Lumbiganon P, Landoulsi S, et al. Active management of the third stage of labour with and without controlled cord traction: a randomized, controlled, non-inferiority trial. 2012; 379: 1721-7.

[3] Johnson R, Taylor W. Skills for midwifery practice. $3^{\text {rd }}$ ed. Edinburgh: Elsevier; 2010.

[4] Deneux-Tharaux C, Sentilhes L, Maillard F, et al. Effect of routine controlled cord traction as part of the active management of the third stage of labour on postpartum haemorrhage: multicentre randomized controlled trial (TRACOR). BMJ. 2013; 346: f1541. PMid: 23538918. https://doi.org/10.1136/bmj.f1541

[5] Artymuk V, Surina N, Kolesnikova B, et al. Active management of the third stage of labor with and without controlled cord traction: a randomized controlled study. Int J Gynecol Obstet. 2012; 119: S2845. https://doi.org/10.1016/S0020-7292(12)60497-4

[6] Ministry of Health, NSW Health Guideline. Maternity - Indications for Placental Histological Examination, 2014; 006: 1-10. Available from: http://www.health.nsw.gov.au/policies/

[7] Stables D, Rankin J. Physiology in childbearing with anatomy and related biosciences, $3^{\text {rd }}$ ed. Edinburgh: Elsevier; 2010.

[8] Blackburn S. Physiological third stage of labour and birth at home. Edwins J. (Ed.). Community midwifery practice. Blackwell: Oxford, 2008.

[9] Sudha A. Study to assess the effectiveness of structured teaching program regarding placental examination among staff nurses at selected hospital, Bangalore. 2008.

[10] Dhurgadevi A. Study to assess the effectiveness of structured teaching program on knowledge of placental examination among III year BSc nursing students in a selected nursing college at Bangalore. A thesis submitted to College of Nursing, Bangalore, Karnataka. 2010.

[11] WHO. Maternal Mortality-Fact Sheet $\mathrm{N}^{\circ} 348$. Updated November 2015.

[12] Brown H, Small M. Overview of maternal mortality and morbidity. 2016. Available from: https//www uptodate.com/contents/o verview/-of-maternal-mortality-and-morbidity

[13] Filippi C, Chou D, Ronsmans C. Levels and Causes of Maternal Mortality and Morbidity. Reproductive, Maternal, Newborn, and Child Health: Disease Control Priorities. 2016, $3^{\text {rd }}$ ed. (Volume 2). Washington (DC): The International Bank for Reconstruction and Development /the World Bank; 2016 Apr. Chapter 3. Available from: https://www.ncbi.nlm.nih.gov./pubmed?term=Ronsmans

[14] National Women's Health Clinical Guideline/Recommended Best Practice. Retained Placenta.

[15] Yokoe DS, Christiansen CL, Johnson R, et al. Epidemiology of and Surveillance for Postpartum Infections. Emerging Infectious Diseases. 2001; 7(5): 837-841.

[16] Hassan H. Infertility profile, psychological ramifications and reproductive tract infection among infertile women, in northern Upper
Egypt. Journal of Nursing Education and Practice. 2016; 6(4): 92 108. https://doi.org/10.5430/jnep.v6n4p92

[17] England M. Review of Psychotherapy for the advanced practice psychiatric nurse. Perspectives in Psychiatric Care. 2008; 44(3): 219-220. https://doi.org/10.1111/j.1744-6163.2008.00179.x

[18] Webster S, Gallagher S, Brown P, et al. The perceptions of nurses in their management of patients experiencing anxiety. Journal of Nursing Education and Practice. 2012; 2(3): 38-45.

[19] Nasr E, Hassan H. Association between quality of family planning services and client's satisfaction level in maternal and child health centers in Port Said city. Journal of Nursing Education and Practice. 2016; 6(1): 85-99.

[20] Gomez R, Romero R, Medina L. Cervicovaginal fibronectin improves the prediction of preterm delivery based on sonographic cervical length in patients with preterm uterine contractions and intact membranes. Am J Obstet Gynecol. 2005; 192: 350-359. [Erratum, Am J Obstet Gynecol. 2005; 193: 308-9.] PMid: 15695971. https://doi.org/10.1016/j.ajog. 2004.09.034

[21] Hassan H, Nasr E. Improving nurses' knowledge and skills regarding tocolytics for inhibiting preterm labor. Clinical Nursing Studies. 2017; 5(1): 1-12. https://doi.org/10.5430/cns .v5n1p1

[22] Donald S. Physiology and management of the third stage of labour: In: Fraser D, Cooper M. (Eds.) Myles textbook for midwives. $15^{\text {th }}$ ed. Edinburgh: Elsevier; 2009.

[23] Farag M. School of Public Health University of Saskatchewan. 2012.

[24] Farag M. Belfer Center for Science and International Affairs, Harvard University. 2008.

[25] Royal hospital for women. Clinical policies, procedures \& guidelines, Obstetrics Clinical Guidelines Group. 2009.

[26] Zuccollo J. A practical approach to placental examination. Birth 2010; 12(4): 39-41.

[27] Women and newborn health service, King Edward Memorial Hospital, Placenta: indications for histopathological and Microbiological examination, Clinical Guidelines: Obstetrics and Midwifery, Department of Health Western. Perth Western Australia. 2015: 25. Available from: http://www.kemh.health.wa.gov.au/genera l/disclaimer.htm

[28] Hill A. Embryology Placenta - Abnormalities. 2016. Available from: https://embryology.med.unsw.edu.au/embryology/ index.php/PlacentaAbnormalities

[29] Wong W. Postpartum Infections. 2015. Available from: http: //emedicine.medscape.com/article/796892-overview

[30] Fraser DM, Cooper MA. Myles Textbook for Midwives, $18^{t h}$ ed. Elsevier science limited; 2013. 518 p.

[31] Kennedy M, Joshi M, Brayshaw S. Examination of the placenta. Mid Essex Hospital Services (NHS), Obstetrics and Gynaecology. 2014; 1(1).

[32] The Royal Berkshire Hospital. Practice Guideline for the Examination of the Placenta Afterbirth. 2014. 